\title{
Revesz syndrome revisited
}

\author{
Michael Karremann ${ }^{1 *}$ (1), Eva Neumaier-Probst ${ }^{2}$, Frank Schlichtenbrede ${ }^{3}$, Fabian Beier ${ }^{4}$, Tim H. Brümmendorf ${ }^{4}$, \\ Friedrich W. Cremer ${ }^{5}$, Peter Bader ${ }^{6}$ and Matthias Dürken ${ }^{1}$
}

\begin{abstract}
Background: Revesz syndrome (RS) is an extremely rare variant of dyskeratosis congenita (DKC) with only anecdotal reports in the literature.

Methods: To further characterize the typical features and natural course of the disease, we screened the English literature and summarized the clinical and epidemiological features of previously published RS cases. In addition, we herein describe the first recorded patient in central Europe.

Results: The literature review included 18 children. Clinical features are summarized, indicating a low prevalence of the classical DKC triad. All patients experienced early bone marrow failure, in most cases within the second year of life (median age 1.5 years; 95\% Cl 1.4-1.6). Retinopathy occurred typically between 6 and 18 months of age (median age 1.1 years; $95 \% \mathrm{Cl} 0.7-1.5)$. The incidence of seizures was low and was present in an estimated $20 \%$ of patients. The onset of seizures was exclusively during early childhood. The Kaplan-Meier estimate of survival was dismal (median survival 6.5 years; $95 \% \mathrm{Cl} 3.6-9.4$ ), and none of the patients survived beyond the age of 12 years. Stem cell transplantation (SCT) was performed in eight children, and after a median of 22 months from SCT four of these patients were alive at the last follow up visit.
\end{abstract}

Conclusion: RS is a severe variant of DKC with early bone marrow failure and retinopathy in all patients. Survival is dismal, but stem cell transplantation may be performed successfully and might improve prognosis in the future.

Keywords: Bone marrow failure, Cerebellar hypoplasia, Exudative retinopathy, Growth retardation, Pancytopenia, Revesz syndrome, Shelterin, Telomere, TINF2

\section{Background}

Dyskeratosis congenita (DKC) is a multisystem disorder classically defined by a triad of clinical symptoms including oral leukoplakia, hyperpigmented reticular skin lesions, and nail dystrophy, but the clinical features are highly variable $[1,2]$. Individuals are prone to develop bone marrow failure, malignancies, immunodeficiency, and pulmonary complications. Less common features include dental and eye abnormalities, esophageal stenosis, urethral stenosis, avascular necrosis of the femur and/ or humerus, osteopenia, enteropathy, and liver disease

\footnotetext{
*Correspondence: michael.karremann@umm.de

1 Department of Pediatrics, University Medical Center Mannheim, Theodor-Kutzer-Ufer 1-3, 68167 Mannheim, Germany

Full list of author information is available at the end of the article
}

[3]. Within this wide spectrum of clinical phenotypes, some rare entities represent distinct variants of DKC, namely Høyeraal-Hreidarsson syndrome (HHS, OMIM \#305000) and Revesz syndrome (RS; OMIM \#268130) [4]. Cerebroretinal microangiopathy with calcifications and cysts (CRMCC; formerly Coats plus syndrome, OMIM \#612199) is another disorder of telomere maintenance, with distinct overlap to RS in clinical presentation [5].

Høyeraal-Hreidarsson syndrome is a severe variant of DKC [6]. Patients typically harbor intrauterine growth retardation, microcephaly, and cerebellar hypoplasia. The further course of disease is characterized by developmental delay, and early, progressive bone marrow failure, with the latter leading to death during childhood $[7,8]$. First described in 1988 by Tolmie et al. $[9,10]$, extensive intracranial calcifications, leukodystrophy, and bilateral original author(s) and the source, provide a link to the Creative Commons licence, and indicate if changes were made. The images or other third party material in this article are included in the article's Creative Commons licence, unless indicated otherwise in a credit line to the material. If material is not included in the article's Creative Commons licence and your intended use is not permitted by statutory regulation or exceeds the permitted use, you will need to obtain permission directly from the copyright holder. To view a copy of this licence, visit http://creativecommons.org/licenses/by/4.0/. The Creative Commons Public Domain Dedication waiver (http://creativeco mmons.org/publicdomain/zero/1.0/) applies to the data made available in this article, unless otherwise stated in a credit line to the data. 
exudative retinopathy characterize CRMCC. Other features, including bone marrow failure during adolescence and early adulthood, increased risk of intestinal bleeding and bony lesions have been described [11-14], and may help to clinically discriminate CRMCC from RS [15]. The latter entity was first described in 1992 [16], and is characterized by early bone marrow failure and bilateral exudative retinopathy. It features skin, hair, and nail abnormalities, intracerebral calcifications, cerebellar hypoplasia, and ataxia. In addition, children may be born small for gestational age and exhibit developmental delay. Death usually occurs during early childhood [17-20].

All variants of DKC share dysfunctional telomere maintenance, resulting in a reduced protection from cellular senescence and accelerated exhaustion of (in particular) high turnover tissues, genetic instability, and increased frequency of secondary malignancy. To date, a minimum of 11 genes of the DKC complex have been shown to harbor mutations accounting for the different subtypes of DKC. However, the association of genotype and phenotype is highly variable. While patients with classical DKC harbor mutations in ACD, CTC1, DKC1, NHP2, NOP10, PARN, RTEL1, TERC, TERT, TINF2, and WRAP53 [4], several of these mutations may also underlay the more severe HHS [6, 21]. In contrast, CRMCC and RS are linked to mutations in distinct genes, namely the CST telomere replication complex component 1 (CTC1), and in the TRF1-interacting nuclear factor-2 (TINF2), respectively [22, 23].

In RS, mutations in TINF2 at chromosome 14q11.2 result in dysfunctional TIN2 protein leading to impaired telomere protection by the shelterin complex [24]. Patients harbor extremely short telomeres, even compared to patients with classical DKC [3, 20]. Mutations in additional genes reported in DKC patients affecting the telomerase complex have not been associated with RS. Nevertheless, the same mutations in TINF2 may be found in classical DKC patients presenting clinically without the distinct RS phenotype, hence, the genotype alone is not able to define RS [20, 25, 26]. Discriminating RS from other variants solely by clinical criteria may also be challenging. Furthermore, the clinical features vary significantly in individual patients, and overlap of RS with other DKC variants $[27,28]$ or alternate disease entities, such as Fanconi anemia or others, is common [29-32]. In addition, accelerated telomere shortening can also be observed in non-hereditary clonal and non-clonal disorders affecting individual (mostly the hematopoietic) stem cell compartments [33].

To the best of our knowledge, no more than 17 patients with RS, together with sufficient clinical data, have been published in the English literature to date [3, 16-20, 23, 34-42]. Reviewing these cases and reporting the first patient in central Europe, the present work aimed to further characterize this rare entity.

\section{Patients and methods}

\section{Mutational and telomere length analysis}

The average length of telomere repeats in peripheral blood lymphocytes and granulocytes of the patient (at the age of 15 months), as well as her parents and siblings, was determined by flow-FISH as previously described [43]. Molecular analysis included screening for genetic alterations within exon six of the TINF2 gene.

\section{Literature search}

To identify previously published patients with RS, an electronic PubMed search of the English literature was performed using the terms "bone marrow failure", "aplastic anemia", and "pancytopenia", each in combination with "retinopathy". In addition, PubMed was searched for "Revesz syndrome", and "TINF2". Further case reports were included, if referred to in the relevant literature. In case of insufficient clinical information within the publications, the respective corresponding authors were contacted and requested to provide missing data. Individuals who provided further information are mentioned in the acknowledgement section.

\section{Statistical analyses}

Statistical analysis was performed using IBM SPSS Statistics ${ }^{\circledR}$ version 25 (IBM, Armonk, NY, USA). Survival, as well as the time-dependent cumulative risk to develop bone marrow failure, retinopathy, and seizures, was estimated by Kaplan-Meier analysis. Patients were censored in case of death, and at the age of the last reported visit. All patients were defined regarding gender (male/female), and potential features of RS (present/absent/unknown). $\mathrm{A} \mathrm{chi}^{2}$-test was applied to compare the sex of patients to an equal gender distribution. Due to the small number of patients, the retrospective character of the study, and a potential bias since the underlying case reports might not be representative, the prevalence of these features was discussed cautiously. Statistical numbers are intended to be "hypotheses generating". Details are given in Table 1.

\section{Results \\ Case report}

The female infant was delivered preterm after 33 gestational weeks (birth weight $1360 \mathrm{~g}, \mathrm{P} 10$ ) as the 4th child of non-consanguineous parents with Caucasian descent. Apart from a mild oligohydramnios and suspected growth retardation, pregnancy was uneventful. Delivery and postnatal course were without complication and, in particular, no respiratory support was required. 


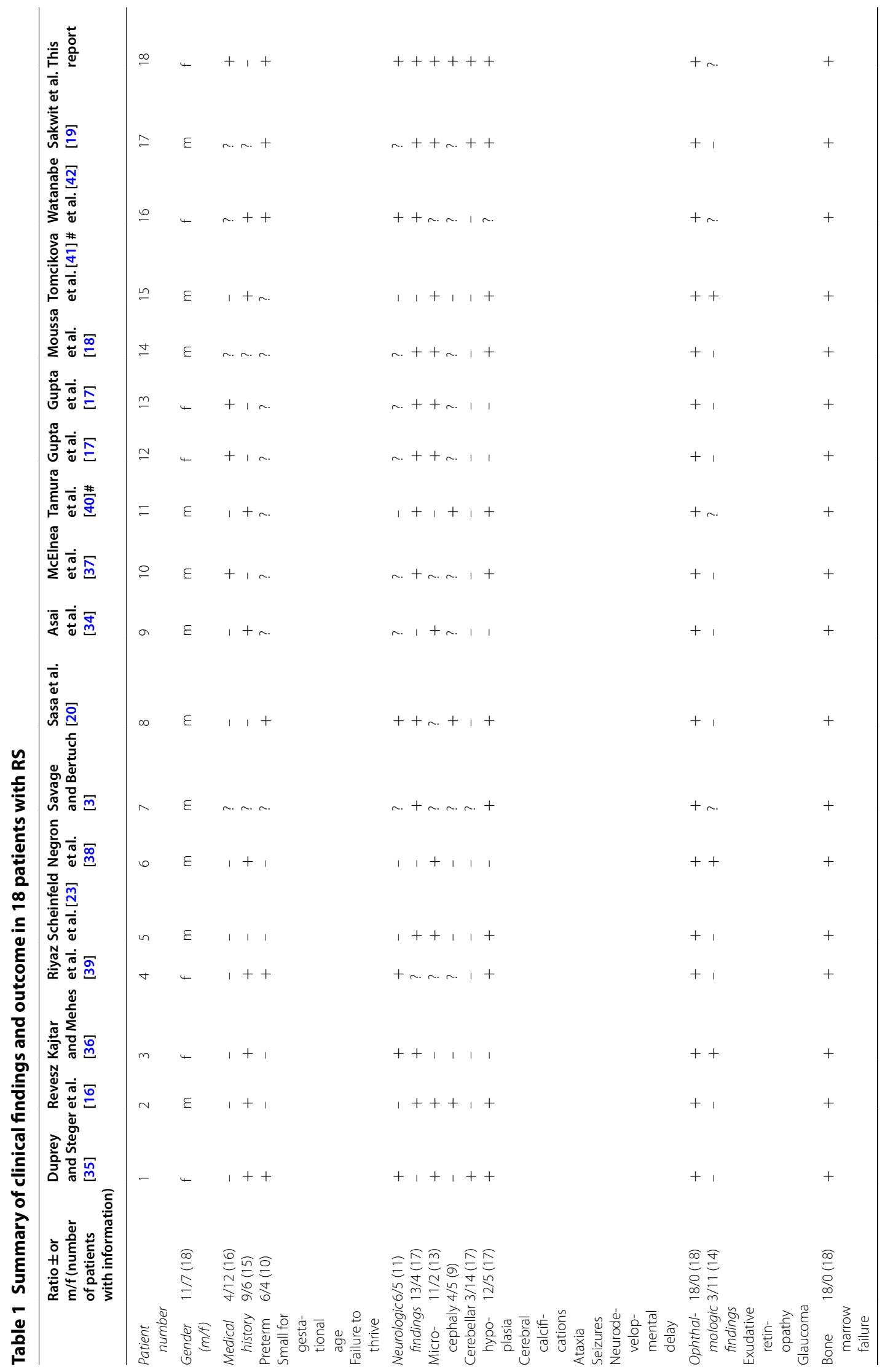




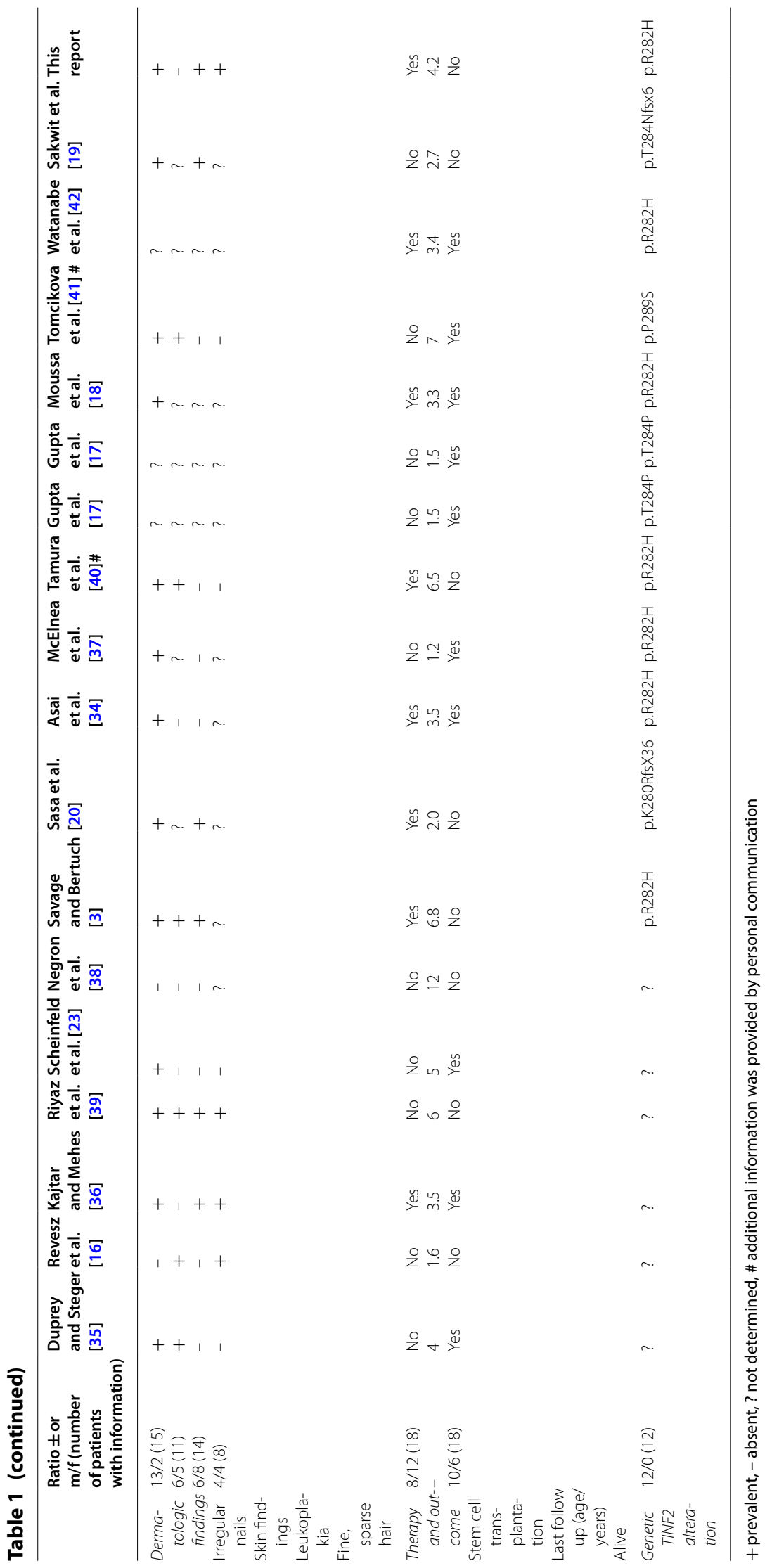


At the age of $2 \frac{1}{2}$ months, the girl experienced her first partial seizure following vaccination. MRI imaging revealed cerebellar hypoplasia and periventricular white matter changes, at this time attributed to prenatal hypoxemia (Fig. 1). Due to recurrent seizures, an anticonvulsive treatment with levetiracetam and topiramate was initiated. Pancytopenia was first seen at the age of 9 months, during an episode of bronchitis (leukocytes 2600/ $\mu \mathrm{L}$, hemoglobin $8.7 \mathrm{~g} / \mathrm{dL}$, thrombocytes $15,000 / \mu \mathrm{L})$. Over the next few months, the blood count continued to worsen to very severe neutropenia (absolute neutrophil count $<200$ / $\mu \mathrm{L})$, resulting in platelet transfusions twice weekly and erythrocyte transfusions every other week. Diagnostic workup showed bone marrow aplasia without signs of myelodysplasia or cytogenetic abnormalities. Metabolic diseases and infections, as well as Fanconi anemia and paroxysmal nocturnal hemoglobinuria, were ruled out as the underlying pathology for the observed bone marrow failure.

Soon after birth, an exudative retinopathy had been diagnosed and treated with repeated intraocular Bevacizumab injections. Furthermore, the patient exhibited a mild psychomotor developmental delay and a failure to thrive, e. g. body weight of $5 \mathrm{~kg}(<\mathrm{P} 3)$, length of $62 \mathrm{~cm}$ $(<\mathrm{P} 3)$, and head circumference of $40 \mathrm{~cm}(<\mathrm{P} 3)$ at the age of 10 months. In contrast to her siblings, she had fine, sparse hair, but normal skin and nails (nail dystrophy developed by the age of 4 years). A second MRI of the brain at the age of 1 year confirmed cerebellar hypoplasia, but also revealed multiple demyelinating areas, both in the periventricular and subcortical white matter, in part with calcifications (Fig. 2 and Additional file 1: Figure 1). In addition, a distinct hypoplasia of the corpus callosum developed, most likely due to increasing leukoencephalopathy (Additional file 2: Figure 2).

The diagnosis of RS was finally suspected based on of the clinical signs and MRI findings. This was confirmed by telomere length analysis, which revealed extremely short telomeres of 2.47 kilobases $(\mathrm{kb})$ in peripheral blood lymphocytes and $2.48 \mathrm{~kb}$ in peripheral blood granulocytes, both substantially below the first percentile of healthy controls. Both parents and three siblings exhibited telomere lengths within the normal range (Fig. 3). Mutation analysis detected a genetic alteration in exon six of TINF2 with a previously published base change c.845G > A, leading to the amino acid change Arg282His.

The child underwent allogeneic bone marrow transplantation (SCT) from a healthy HLA-identical sibling at the age of 17 months. The conditioning regimen included fludarabine $\left(30 \mathrm{mg} / \mathrm{m}^{2}\right.$ day -7 to -3$)$, cyclophosphamide $(30 \mathrm{mg} / \mathrm{kg}$ day -6 to -3$)$, and anti-thymocyte globulin $(20 \mathrm{mg} / \mathrm{kg}$ day -4 to -2$)$. Apart from an invasive aspergillosis of the lungs and a mild acute graftversus-host disease, no serious complications occurred. Hematological engraftment was achieved after day +11 , and day+55 for granulocytes and thrombocytes, respectively. The girl exhibited an early T-cell expansion with $>500 \mathrm{CD} 3+$ cells $/ \mathrm{mL}$ at day +60 . A reactivation of Adenovirus detected by PCR at day +70 resolved spontaneously. Aspergillus infection was treated with intravenous liposomal amphotericin B and caspofungin, followed by an oral treatment with voriconcazole until 10 months from SCT, resulting in residual lesions in both upper pulmonary lobes. Further mild and non-persisting complications within the first year from SCT included Epstein-Barr virus reactivation (treated by one single

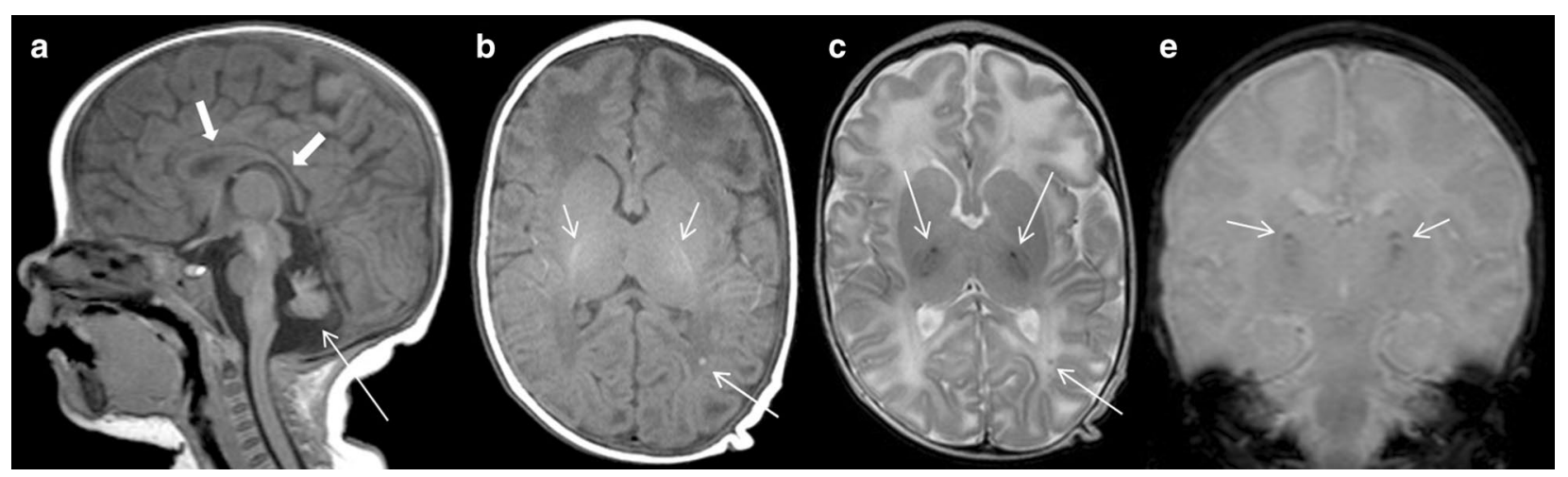

Fig. 1 Initial MRI at the age of 2.5 months performed after the first partial seizure. Sagittal T1-weighted MRI image demonstrates cerebellar hypoplasia with an emphasis on the vermis and tonsils (arrow) and consecutive enlargement of the cerebrospinal fluid (CSF) spaces. The corpus callosum has a normal shape and size (thick arrow) (a). Transversal T1-weighted MRI image shows normal myelination within the internal capsule concealing the punctuate high signal (b) corresponding to the low signal areas in the T2-weighted (c) and T2*-weighted images within the thalami (d). These areas of signal abnormality correspond to calcifications. Also note the abnormal signal intensity in the frontal lobes (b, c) corresponding to leukencephalopathic areas also seen in the follow ups. At this point there was no administration of gadolinium contrast material 

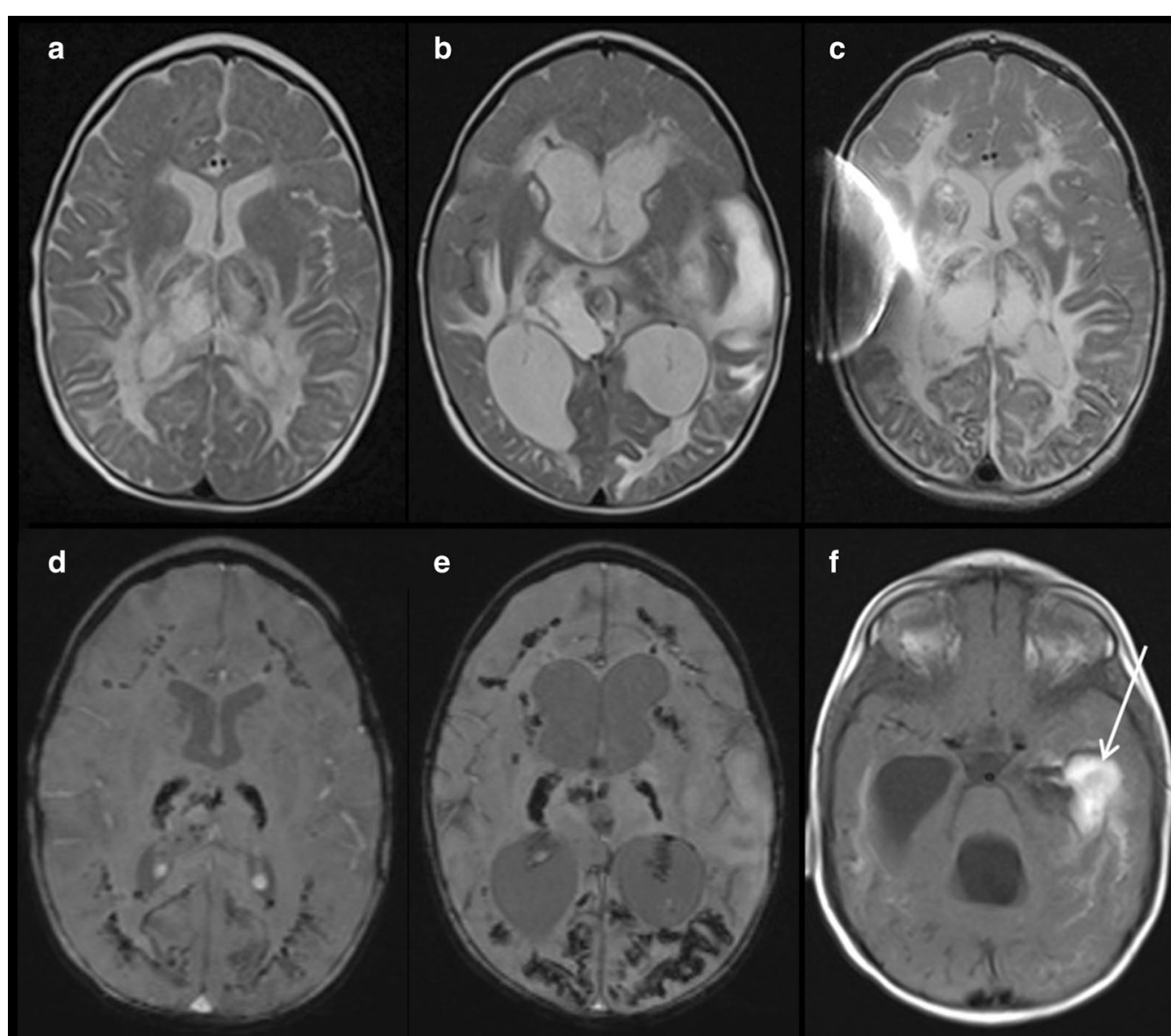

Fig. 2 Axial T2-weighted images demonstrate progression of symmetric white matter lesions periventricular, within the thalamus, in the internal capsule, and the basal ganglia at the age of 1 year (a), 2 years (b), and 3.8 years (c). The corresponding axial susceptibility-weighted images (SWI) demonstrated progressive foci with susceptibility artefacts distributed symmetrically within the basal ganglia, the thalami, and on the border between gray and white matter $(\mathbf{d}, \mathbf{e})$, corresponding to calcifications. At the age of 2 years the patient suffered from a hemorrhage at the level of the left temporal horn with intraventricular breakthrough, shown as an area of high intensity (arrow) on the T1-weighted image (f), and hydrocephalic congestion (b, f), resulting in the need for ventricular-peritoneal shunt insertion. The artefact on the right side is due to the implanted shunt (c)
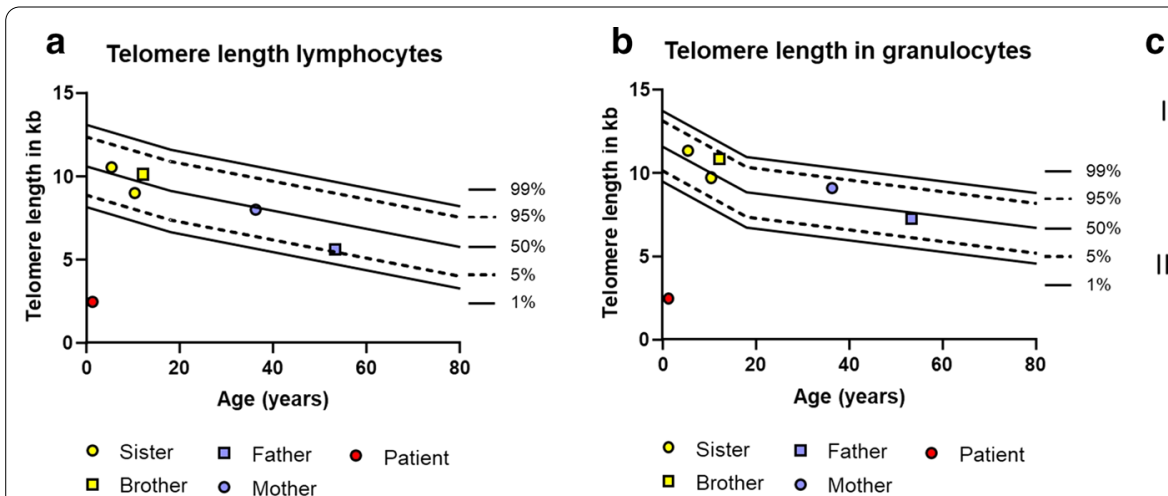

C

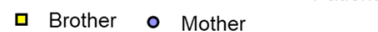

a Brother o Mother

I.

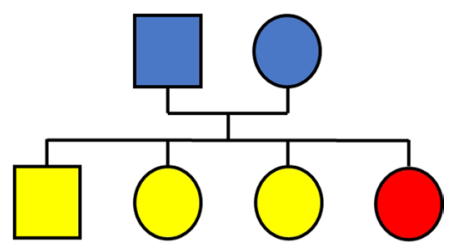

Fig. 3 Telomere length analysis of the patient (red), her siblings (yellow), and parents (blue) demonstrates the shortening in the patient's a lymphocytes and $\mathbf{b}$ granulocytes, substantially below the first percentile of age. In contrast, the results of her parents and siblings were within normal limits. c Pedigree. Circle indicates female, square indicates male gender 
infusion of rituximab), and persisting mild thrombocytopenia, most likely attributed to anticonvulsive treatment.

During the second year after SCT, the girl experienced progressive abdominal pain crises resulting predominantly in malnutrition and further failure to thrive. The cause of these could not be clarified, but graft versus host disease of the gut was ruled out. In addition, a spontaneous intraventricular hemorrhage occurred at the age of 2 years, finally resulting in hydrocephalus and a need for ventricular-peritoneal shunting (Fig. 2f). At this time, blood count and hemostaseologic parameters were within normal limits. Therefore, we propose that this bleeding event was most likely due to an increased intracerebral pressure during extensive crying, and perhaps fostered by an increased fragility of the intracerebral vessels.

During the girl's 3rd and 4th year of life, psychomotor delay remained despite extensive training. Visual acuity worsened, resulting in a nearly complete loss of vision at the age of 3 years (corresponding retinal detachment shown in Additional file 3: Figure 3). Also, somatic development was seriously delayed. At the age of 4 years, the patient experienced severe aspiration pneumonia, and finally passed away due to refractory lung failure.

\section{Literature search}

In addition to the patient reported in this work, a literature search revealed 22 cases of RS. Five patients were excluded, since only very limited clinical data were available. Additional information concerning missing clinical data within the references was provided by the respective authors of the case reports on request for patient \#11 and \#15. Patient \#1, with features of RS published in 1988 , was included, even though this was published prior to the characterization and definition of Revesz. Thus, 17 patients from the literature were eligible for evaluation.

\section{Patients characteristics}

In total, this study reviewed 18 cases of RS (Table 1); seven females and 11 males, resulting in a male predominance of 1.6:1 (not significant). Of note, stigmata belonging to the classical clinical DKC triad of oral leukoplakia, hyperpigmented skin findings, and nail dystrophy were prevalent in only $43 \%(n=6 / 14), 55 \%(n=6 / 11)$, and $87 \%$ $(n=13 / 15)$ of patients with information, respectively. In contrast to classical DKC, all cases of RS represented de novo mutations with unaffected parents, reflecting the severe course and early death in this disease.

The very severe prognosis of RS could be substantiated in the present work. Kaplan-Meier analysis estimated a median survival of only 6.5 years (95\% CI 3.6-9.4), and no patient beyond the age of 12 years was identified in the literature (Fig. 4). Patients died

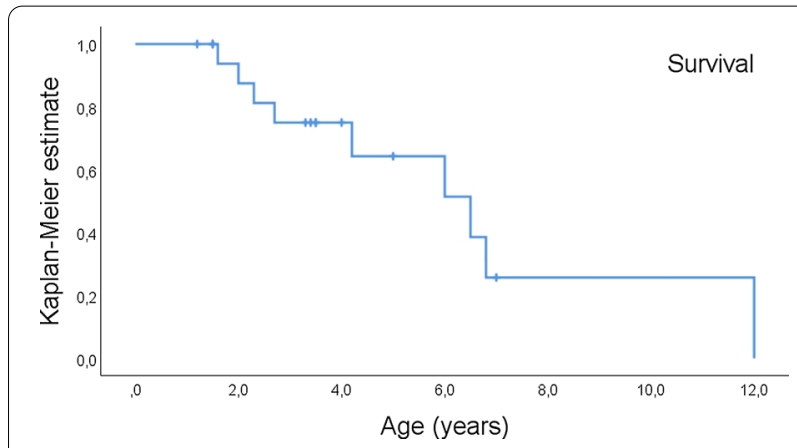

Fig. 4 Kaplan-Meier estimate of survival in 18 patients with Revesz syndrome. Median survival was 6.5 years (95\% Cl 3.6-9.4)

from BMF in most cases, but refractory lung failure was another cause of death in some cases. Bone marrow failure occurred in all patients between birth and the age of 6 years, in most cases within the second year of life (median age 1.5 years; 95\% CI 1.4-1.6, Fig. 5a). BMF lead to stem cell transplantation in eight patients, four of whom were still alive at the end of follow up 1 month (\#3), 20 months (\#9), and 2 years (\#14 and \#16) from SCT. Details on the conditioning regimen were specified in four patients; all underwent a reduced conditioning regimen, including fludarabine $(100-180 \mathrm{mg} /$ $\mathrm{m}^{2}$ ), cyclophosphamide $(100-120 \mathrm{mg} / \mathrm{kg})$, and anti-thymocyte globulin. Patients with this regimen tolerated SCT well without severe early transplantation-related toxicity. All patients developed retinopathy, most likely between the ages of 6 and 18 months (median age 1.1 years; $95 \%$ CI $0.7-1.5$; Fig. $5 \mathrm{~b}$ ). Despite treatment, retinopathy led to a severe loss of visual acuity in most patients. Glaucoma occurred in three cases. Frequent features of RS include neurological and neuroanatomical abnormalities. In the present cohort, cerebellar hypoplasia $(76 \%, \mathrm{n}=13 / 17)$ and intracranial calcifications $(85 \%, \mathrm{n}=11 / 13)$ were common features, whereas microcephalia and ataxia were reported less often (Table 1). Only three patients (unknown in one) experienced seizures, that developed exclusively during early childhood, resulting in a cumulative incidence rate of 20\% (SD 10.7; Fig. 5c). Our study substantiated neurodevelopmental delay and/or mental retardation to be a frequent feature of RS, and this was present in $71 \%$ of patients $(n=12 / 17)$, frequently emerging during infancy. However, learning deficits were often mild, and absent in others, indicating that neurocognitive impairment is not an obligatory feature of the syndrome. Of note, intracranial hemorrhage was detected in three patients during the course of the disease and might represent a yet underrecognized cerebrovascular vulnerability. Patients with RS are born small for gestational 

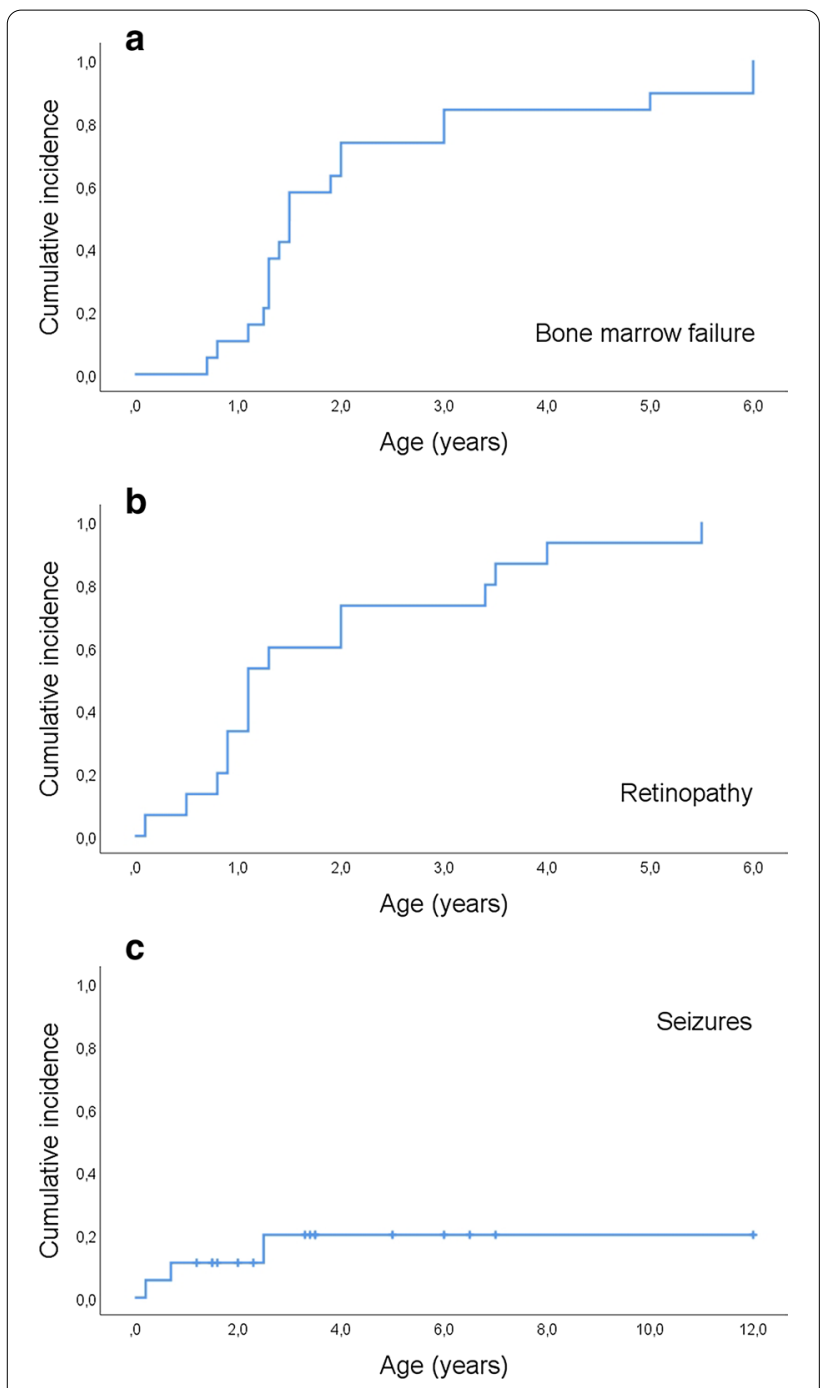

Fig. 5 Estimated cumulative incidence of various features of RS: a All patients developed bone marrow failure (BMF) by the age of 6 years. Time of diagnosis was available in 16 patients, with BMF occurring most frequently in the second year of life (median age 1.5 years; $95 \%$ Cl 1.4-1.6). b Accordingly, retinopathy was present in all cases (time of diagnosis was available in 15 patients). Most children developed retinopathy between the ages of 6 and 18 months of life (median age 1.1 years; $95 \% \mathrm{Cl} 0.7-1.5$ ). c Only three patients (unknown in two) experienced seizures. These developed exclusively during early childhood, resulting in an estimated cumulative incidence rate of 20\% (SD 10.7)

age and/or preterm, resulting in a mean birth weight of $1950 \mathrm{~g} \pm 410$ (SD), and one out of three patients failed to thrive (Table 1).

Genetic mutational analysis was available in $66 \%$ of patients $(n=12)$ and was performed in all patients that were published since 2010. All of these harbored a TINF2 mutation and the underlying alterations were restricted to exon six. The most frequent mutation was c.845G > A, a missense mutation resulting in an amino acid substitution of Alanine to Histidine at position 282 of the TIN2 protein. Further mutations included two heterozygous deletions resulting in a frameshift and premature stop codon leading to truncated TIN2 proteins (c.839delA, p.K280RfsX36, patient \#9; and c.851-855 del CAGTC; p.T284Nfsx, patient \#17) and alternate missense mutations at position 284 (c.850A > C; p.T284P; patients \#12, 13) and 289 (c.865C > T, p.P289S, patient \#15) of the TIN2 protein. Hence, all mutations were located between amino acid 280 and 289.

Telomere analysis was available in seven patients. All presented with very short lengths, reported as "below the first percentile for their age" (patients \#10, \#12, \#13, $\# 20$ ), reported in absolute numbers of $2.3-2.8 \mathrm{~kb}(\# 8)$ and $2.5 \mathrm{~kb}(\# 20)$ and/or given as relative shortening of -5.7 SD (\#16).

\section{Discussion}

Revesz syndrome is an extremely rare disorder, and to date, patients have only been published anecdotally. Therefore, the present work aimed at further characterization of this rare entity by summarizing the clinical findings of 17 previously published cases of RS $[3,16-20,23$, 34-42], and presenting the one further case reported in this work. The latter represents the first published patient from central Europe.

\section{Medical history and clinical signs}

In the present cohort, we found a slight and non-significant male predominance. This is far less pronounced compared to DKC, with its often X-linked inheritance [2]. Given the autosomal background in RS, we would agree with Gupta and coworkers who state an equal gender distribution in RS [17]. In all, our findings argue against previous presumptions of a considerable male predominance of 3:1 [18].

Looking into the patients' medical history, growth retardation, either prevalent at birth or a failure to thrive was prevalent in most cases. Four children were delivered preterm, and of note, those did not present small for gestational age. Unfortunately, information on further somatic development was available for only one of these children, and this girl experienced severe failure to thrive soon after birth, indicating that growth retardation starts during late pregnancy or postnatally. However, some children regained underweight. Hence, growth retardation is common, but not a general trait in patients with RS.

Nail dystrophy was the most frequent feature of the clinical DKC triad. In line with findings in classical DKC, typical skin pigmentation and oral leukoplakia were even less frequent [44], resulting in the complete clinical triad 
in only two cases, in contrast to $35 \%$ in DKC [44]; hence, the clinical signs of the DKC triad seem less common in patients with RS [45]. This might be confusing, since the prevalence of these correlate with a more severe course of the disease and early onset BMF in classical DKC [4, 44]. However, the seemingly low incidence in RS is in line with previous assumptions [26] and might well be due to the young age at diagnosis and early death of these patients, since the DKC triad may develop with age and sometimes following BMF [4, 45] between the ages of five and 13 years $[2,46]$. Accordingly, in patients \#11 and \#18 of our cohort, nail dystrophy was absent when the diagnosis of RS was made but developed during course of disease. Furthermore, this review might underestimate the prevalence, since findings may be subtle and not all case reports commented on these signs. We would therefore suggest careful screening for signs of the DKC triad in patients with suspected RS, not only at time of initial diagnosis but also at older ages. However, diagnosis of RS is based on additional features and a lack of DKC signs, especially in young children, should not preclude from providing a diagnosis [4].

As in DKC, patients with RS may be prone to developing secondary malignancies [47]. Most likely due to the short survival time, none of the patients from the present report experienced such complications. However, once survival might improve, patients should be monitored accordingly.

\section{Bone marrow failure}

TINF2 mutations have been linked to severe BMF [48]. Accordingly, BMF, occurring at an even younger age than previously suspected, is a general trait of RS [18]. Reflecting the most severe course of disease, BMF was most likely to develop within the second year of life and, in all cases, developed by the age of 6 years (Fig. 5a).

Stem cell transplantation (SCT) was performed in eight patients from the present cohort, and four of these were still alive at the last documented visit. Hence, SCT should be offered to patients, if required clinically, potentially resulting in improved survival in the future. Various conditioning regimens, stem cell sources, and donors have been published [3, 18, 20, 34, 36, 40, 42]. The authors point out a relevant treatment-related toxicity due to the underlying telomere disorder (particularly affecting the lung), and the approach should take into account experiences in DKC patients. In this regard, Ostronoff suggested a reduced intensity conditioning (RIC) regimen including fludarabine, cyclophosphamide, and anti-thymocyte globulin in DKC patients [49]. Within the present cohort, four of the eight cases, including our patient, underwent this regimen with only limited acute SCT-associated toxicity [34, 40, 42]. Hence, we suggest applying this conditioning regimen in patients with RS, but still SCT in RS remains a high-risk transplantation and should, therefore, be carried out by experienced centers only.

\section{Pulmonary disease}

Lung complications contribute to treatment-related mortality, especially following SCT in adult DKC patients [46, $48,50]$. Accordingly, two deaths in this series occurred due to terminal lung failure 2 years [this report] and 4.5 years [40] after the date of the successful SCT. Conditioning regimens with potential pulmonary toxicity should, therefore, be avoided to prevent worsening of occult lung disease [42, 51]. Given that pulmonary interstitial fibrosis is independently attributed to TINF2mutations $[49,52,53]$, lung disease due to insufficient telomere maintenance may be regarded as an obligatory late sequela in patients with RS also without SCT [52]. Accordingly, in DKC, sporadic lung disease may develop within the second and third decade, but with a median of 4.7 years following SCT [53]. Only one of the 10 cases without SCT in the present review experienced lung failure (at the age of 12 years), most likely due to the short survival time of the others [38]. Therefore, this complication should not preclude one from performing SCT, but patients should be educated and monitored accordingly. Potentially, early and aggressive interventions in case of respiratory symptoms might further improve survival (especially following SCT) in the future.

\section{Retinopathy}

In the present study, exudative retinopathy occurred during infancy and early childhood, most likely between the ages of 6 and 18 months (Fig. 5b). Some children were born preterm, but the medical history was unlikely to determine an association between retinopathy and prematurity. Hence, RS should be considered in case of Coats-like retinopathy in infants without a typical history. Therapy included photocoagulation $[17,18,20,23$, $34,37,41]$, repeated bevacizumab injections [17, 34], retinocryopexia $[35,36]$, and surgical approaches, including vitrectomy $[17,34,37,41]$ and enucleation, in cases of complete loss of visual acuity with or without painful glaucoma [16, 36, 41]. To date, laser photocoagulation is the preferred mode of therapy, and bevacizumab injections are an alternative [50]. However, in RS-associated retinopathy, most patients will develop a severe loss of visual acuity despite treatment.

Exudative retinopathy is a defining trait of RS [4]. However, there is a huge overlap to alternate entities that may harbor other features of RS, including BMF, failure to thrive, mental retardation, and the cerebral abnormalities. These include patients with DKC and potentially 
mutations other than TINF2, in whom retinopathy may occur occasionally $[28,51,54,55]$. These patients may be discriminated from RS by the less severe course of disease and/or the absence of a TINF2 mutation. In addition, in cases of a familial history of DKC, the diagnosis of RS should be questioned. HHS may be associated with retinopathy [27], mimicking the severe course of RS. However, a familial history of DKC and mutations outside TINF2 may exclude RS and classify these patients as HHS. Moreover, a relevant overlap is found with CRMCC. This disease, formerly called Coats plus syndrome, resembles RS regarding bilateral exudative retinopathy, intracranial calcifications, mucocutaneous abnormalities, and bone marrow failure. It can be discriminated by molecular analysis, since CRMCC is restricted to CTC1 mutations. Clinically, it differs from RS by the prevalence of bony lesions and intestinal bleeding [11-14]. Since SCT is dispensable due to the late onset and often mild course of BMF, discriminating CRMCC from RS is of upmost importance [15]. Further disorders include Fanconi anemia $[31,32,56]$ and rare entities, including mutations in DNAJC21 and ERCC6L2 [29, 30].

Conversely, patients with features of RS including early onset of BMF and TINF2-mutations but lacking exudative retinopathy are published in the literature. These cases differ from RS not only in terms of the ophthalmologic findings, but they also usually exhibit a less progressive course and longer survival. These patients should not be classified as RS [3], but represent variants of autosomal dominant DKC [57-59]. Therefore, accurate clinical evaluation, including verification or exclusion of retinopathy, is essential to classify the disease properly and thereby enabling clear decisions on best possible treatment of the patient.

\section{Central nervous system (CNS) manifestation}

Cerebral calcifications is a central trait of RS [4, 46], reported in all but two patients with clinical information. Hence, even if calcifications may be seen in other entities, including CRMCC, HS, and DKC, this feature in combination with retinopathy, early onset of BMF, and the molecular evaluation of TINF2 is a valuable predictor of RS. Therefore, diagnosis of RS in the absence of cerebral calcifications should be based on other strong criteria. Microcephaly and cerebellar hypoplasia were less common. The latter is usually attributed to HHS [21]. However, cerebral abnormalities are common in TBD and seem to widely overlap between the various DKC variants, with none being specific for a distinct entity [60]. In this regard, we describe the first patient with RS and a hypoplastic corpus callosum. Of note, given that the first MRI soon after birth revealed normal findings, we would hypothesize that the hypoplasia may be attributed to leukoencephalopathy, and the rarity of this trait in RS may be due to the short life expectancy in most patients. In this regard, involution of the corpus callosum may be a general feature in TBI, as it has been described in various patients with HHS [61]. Rarely, gliotic lesions may occur [23].

Of note, three patients of the present cohort experienced intracranial hemorrhages resulting in relevant morbidity $[19,38]$. These bleeds might have been associated with cerebrovascular fragility rather than with low platelets or a plasmatic bleeding predisposition, since cerebral bleeding has been reported in other patients with TINF2 mutations [58], and bleeding from telangiectasias including gastrointestinal hemorrhages is a common trait of other telomere biology disorders [50]. Negron and coworkers hypothesized that reabsorption and healing of such cerebral (micro)bleedings might result in calcifications and, hence, be a pathophysiological trigger of this frequent feature in RS [38].

Scheinfeld has summarized neuroradiologic findings in RS [23]. Herein, we provide further paradigmatic NMR imaging findings.

Neurodevelopmental delay is common in RS, but symptoms may be mild, with "satisfying" neurocognitive development [36], or absent in some patients. In fact, one of the patients was a "good student with above-average intelligence and a skillful violin player" [38]. However, early and repeated neurodevelopmental assessment is indispensable in patients with RS and adequate treatment is essential in cases of pathological delay. Despite the numerous cerebral abnormalities, only few patients experienced seizures, and these developed exclusively during early childhood (Fig. 5c). Hence, in line with other telomere biology disorders [46], epilepsy may occur occasionally, but is not a typical feature of RS.

\section{Genetic background and telomere biology}

$\mathrm{RS}$ is a telomere biology disorder (TBD) within the DKC spectrum resulting in impaired telomere maintenance [62]. The principles of TBD have been summarized by Barbaro, who focused on the various clinical entities [46], whereas Smith has extensively reviewed the biochemical background of telomere maintenance [24].

In contrast to DKC, RS is restricted to mutations in one single gene, namely TINF2 on chromosome $14 \mathrm{q} 12$ [46]. Five different mutations have been published to date, all affecting exon six, similar to all TINF2 mutations described in DKC. The most common germline alteration is c.845G $>\mathrm{A}$, a missense mutation with substitution of guanine to adenine, leading to an amino acid substitution from arginine to histidine at position 282 of the TIN2 protein. Further mutations have been found sporadically that are summarized in Table $1[17,19,34,41]$. 
Dysfunctional TIN2 results in an impaired protection of telomere ends by the shelterin complex and patients harbor extremely short telomeres. Hence, premature shortening of telomere repeats leads to premature cell senescence [62]. Regarding the variant molecular interactions of the mutant TIN2 protein with its natural ligands, the readers are referred to the respective literature [6365]. It is still under debate whether the extent of telomere shortening is generally associated with the severity of symptoms $[66,67]$. Undoubtedly, extremely short telomeres in RS, even compared to other TBD, correlate with a more severe course as well as the early onset of this disorder.

It is noteworthy that not all alterations in TINF2 are pathogenic, hence polymorphisms of the gene exist [66]. Conversely, most patients with TINF2 mutations develop TBDs other than the classical phenotype of RS, including not only 11 to $24 \%$ of DKC patients [3, 20,46], but also HHS, idiopathic pulmonary fibrosis, and aplastic anemia [20, 21, 48, 68, 69]. Even the most frequent TINF2 mutation, p.R282H, is not specific for RS and it is yet unclear which additional mechanisms lead to its full phenotype. Recently, TIN2 was identified as a modifier of telomerase activity via interaction with TPP1/POT1, representing an alternate mechanism of telomere pathology in TINF2 mutations [70], and failure to restore telomere length during early pregnancy was hypothesized to contribute to very short telomeres in severe variants [67]. In addition, varying gene expression within different tissues may be related to clinical phenotypes [17], but there is still much effort required to elucidate the pathogenic biological mechanisms. Therefore, at the present time, clinical features, a mutation within exon six of TINF2, and very short telomeres, e.g. below the first percentile of age, are needed to make an accurate diagnosis.

\section{Conclusion}

We present a comprehensive review on Revesz syndrome by studying previously published patients, in addition to an individual case report first presented here. In summary, RS is characterized by an early onset of exudative retinopathy and bone marrow failure, as well as a very poor survival. Features of the DKC triad, cerebral calcifications, growth retardation, and neurodevelopmental delay are part of the disease in most but not all cases. In addition, we report the first patient from central Europe, who in contrast to all previously published cases, developed hypoplasia of the corpus callosum during early childhood. Since TINF2 mutations are not restricted to RS, clear definition of clinical features is essential for an adequate diagnosis, but symptoms overlap with other entities. Therefore, clinical registries and further genetic studies are needed to elucidate the molecular background of this rare disorder as well as support the exploration of novel therapeutic strategies aiming at improved telomere maintenance [71].

\section{Supplementary information}

Supplementary information accompanies this paper at https://doi. org/10.1186/s13023-020-01553-y.

Additional file 1: Figure 1. Axial T1-weighted images at the age of one year $(a, b)$ and 3.8 years $(c, d)$ before $(a, c)$ and after $(b, d)$ administration of gadolinium contrast material. Primary high signal intensity was observed within the symmetrical calcified areas in the thalamus and occipital lobe, with foci of pathological enhancement in the front right (arrow) (b), and later reinforced enhancement of the primary high intensity areas (d). There was also, not shown, symmetrical enhancement within the partially calcified nucleus ruber.

Additional file 2: Figure 2. Sagittal T2-weighted images demonstrate a reduction in the size of the corpus callosum over time (arrows) due to increasing leukoencephalopathy at one (a) and 3.8 years (b) of age.

Additional file 3: Figure 3. Axial T2-weighted MRI images demonstrate initial normal bulbi at age 2.5 months (a), an abnormal right globe with hemorrhage and detachment at age 2.2 years (b), and an abnormal left globe with $\mathrm{V}$-shaped detachment at age 3.8 years (c).

\section{Acknowledgements}

We greatly acknowledge Shinichi Tamura and Dana Tomcikova for providing additional clinical information on patients \#11 and \#15, respectively.

\section{Authors' contributions \\ M.K. was responsible for study concept, literature review, and wrote the manuscript. E.N.P. provided neuroradiological imaging and F.B. performed tel- omere length analysis and provided Fig. 3. F.S., T.B., F.C., P.B., and M.D. critically reviewed the manuscript for important intellectual content. All authors have read and approved the final version of the manuscript.}

\section{Funding}

Open Access funding enabled and organized by Projekt DEAL. The authors declare no specific grant was awarded for this research from any funding agency.

\section{Availability of data and materials}

The datasets used and/or analyzed during the current study are available from the corresponding author on reasonable request.

\section{Ethics approval and consent to participate}

The present study has been approved by the Institutional Review Board II, Medical Faculty Mannheim, Heidelberg University (2020-832R).

\section{Consent for publication}

The patient described in this manuscript finally died in 2014. Since then, her parents have not visited our hospital again, and we have failed to contact them recently to ask for their consent to the present publication. No identifiable photos of the child have been added to the manuscript, and due to the huge catchment area of our hospital, including a population of approximately two million citizens, identification of the family by the clinical description seems largely excluded. We, however, hope that the case description as well as the representative neuroradiological imaging and the impressive figure concerning telomer shortening may remain in the present review.

\section{Competing interests}

The authors declare that they have no competing interests.

\section{Author details}

${ }^{1}$ Department of Pediatrics, University Medical Center Mannheim, Theodor-Kutzer-Ufer 1-3, 68167 Mannheim, Germany. ${ }^{2}$ Department of Neuroradiology, University Medical Center Mannheim, Mannheim, Germany. 
${ }^{3}$ Department of Ophthalmology, University Medical Center Mannheim, Mannheim, Germany. ${ }^{4}$ Department of Hematology and Oncology, University Hospital of RWTH Aachen, Aachen, Germany. ${ }^{5}$ SYNLAB Center for Human Genetics Mannheim, Mannheim, Germany. ${ }^{6}$ Department of Pediatrics, Pediatric Stem Cell Transplantation, University Hospital Frankfurt, Frankfurt, Germany.

Received: 25 May 2020 Accepted: 22 September 2020

Published online: 23 October 2020

\section{References}

1. Niewisch MR, Savage SA. An update on the biology and management of dyskeratosis congenita and related telomere biology disorders. Expert Rev Hematol. 2019:12(12):1037-52.

2. Garofola C, Gross GP. Dyskeratosis congenita. In: StatPearls [Internet]. Treasure Island (FL): StatPearls Publishing; 2020.

3. Savage SA, Bertuch AA. The genetics and clinical manifestations of telomere biology disorders. Genet Med. 2010;12(12):753-64.

4. Savage SA. Dyskeratosis congenita. In: GeneReviews ${ }^{\circledR}$ [Internet]. Seattle (WA): University of Washington, Seattle; 1993-2020. 2009 Nov 12.

5. Polvi A, Linnankivi T, Kivela T, Herva R, Keating JP, Makitie O, Pareyson D, Vainionpaa L, Lahtinen J, Hovatta I, Pihko H, Lehesjoki AE. Mutations in CTC1, encoding the CTS telomere maintenance complex component 1, cause cerebroretinal microangiopathy with calcifications and cysts. Am J Hum Genet. 2012;90(3):540-9.

6. Olivieri C, Mondino A, Chinello M, Risso A, Finale E, Lanciotti M, Guala A. Clinical heterogeneity in a family with DKC1 mutation, dyskeratosis congenita and Hoyeraal-Hreidarsson syndrome in first cousins. Pediatr Rep. 2017;9(3):7301

7. Walne AJ, Vulliamy T, Kirwan M, Plagnol V, Dokal I. Constitutional mutations in RTEL1 cause severe dyskeratosis congenita. Am J Hum Genet. 2013;92(3):448-53.

8. Ohga S, Kai T, Honda K, Nakayama H, Inamitsu T, Ueda K. What are the essential symptoms in the Hoyeraal-Hreidarsson syndrome? Eur J Pediatr. 1997;156(1):80-1.

9. Tolmie JL, Browne BH, McGettrick PM, Stephenson JB. A familial syndrome with coats' reaction retinal angiomas, hair and nail defects and intracranial calcification. Eye (Lond). 1988;2(Pt 3):297-303.

10. Briggs TA, Abdel-Salam GM, Balicki M, Baxter P, Bertini E, Bishop N, Browne BH, Chitayat D, Chong WK, Eid MM, Halliday W, Hughes I, Klusmann-Koy A, Kurian M, Nischal KK, Rice GI, Stephenson JB, Surtees R, Talbot JF, Tehrani NN, Tolmie JL, Toomes C, van der Knaap MS, Crow YJ. Cerebroretinal microangiopathy with calcifications and cysts (CRMCC). Am J Med Genet A. $2008 ; 146 \mathrm{~A}(2): 182-90$

11. Toiviainen-Salo S, Linnankivi T, Saarinen A, Mayranpaa MK, Karikoski R, Makitie O. Cerebroretinal microangiopathy with calcifications and cysts: characterization of the skeletal phenotype. Am J Med Genet A. 2011;155A(6):1322-8.

12. Sazgar M, Leonard NJ, Renaud DL, Bhargava R, Sinclair DB. Intracranial calcification, retinopathy, and osteopenia: a new syndrome? Pediatr Neurol. 2002;26(4):324-8

13. Goutieres F, Dollfus H, Becquet F, Dufier JL. Extensive brain calcification in two children with bilateral Coats' disease. Neuropediatrics. 1999;30(1):19-21.

14. Painho T, Conceição C, Kjöllerström P, Batalha S. Retinopathy and bone marrow failure revealing Coats plus syndrome. BMC Case Rep. 2018; https://doi.org/10.1136/bcr-2018-224477.

15. Linnankivi T, Polvi A, Makitie O, Lehesjoki AE, Kivela T. Cerebroretinal microangiopathy with calcifications and cysts, Revesz syndrome and aplastic anemia. Bone Marrow Transplant. 2013:48(1):153.

16. Revesz T, Fletcher S, Al-Gazali LI, DeBuse P. Bilateral retinopathy, aplastic anaemia, and central nervous system abnormalities: a new syndrome? J Med Genet. 1992;29(9):673-5.

17. Gupta MP, Talcott KE, Kim DY, Agarwal S, Mukai S. Retinal findings and a novel TINF2 mutation in Revesz syndrome: clinical and molecular correlations with pediatric retinal vasculopathies. Ophthalmic Genet. 2017;38(1):51-60.

18. Moussa K, Huang JN, Moore AT. Revesz syndrome masquerading as traumatic retinal detachment. J AAPOS. 2017;21(5):422-25e1.
19. Sakwit A, Rojanaporn D, Mekjaruskul P, Suriyajakryuththana W, Sasanakul W, Sirachainan N. Novel mutation of the TINF2 gene resulting in severe phenotypic Revesz syndrome. Pediatr Blood Cancer. 2019;66(3):e27557.

20. Sasa GS, Ribes-Zamora A, Nelson ND, Bertuch AA. Three novel truncating TINF2 mutations causing severe dyskeratosis congenita in early childhood. Clin Genet. 2012;81(5):470-8.

21. Glousker G, Touzot F, Revy P, Tzfati Y, Savage SA. Unraveling the pathogenesis of Hoyeraal-Hreidarsson syndrome, a complex telomere biology disorder. Br J Haematol. 2015;170(4):457-71.

22. Anderson BH, Kasher PR, Mayer J, Szynkiewicz M, Jenkinson EM, Bhaskar SS, Urquhart JE, Daly SB, Dickerson JE, O'Sullivan J, Leibundgut EO, Muter J, Abdel-Salem GM, Babul-Hirji R, Baxter P, Berger A, Bonafe L, BrunstomHernandez JE, Buckard JA, Chitayat D, Chong WK, Cordelli DM, Ferreira P, Fluss J, Forrest EH, Franzoni E, Garone C, Hammans SR, Houge G, Hughes I, Jacquemont S, Jeannet PY, Jefferson RJ, Kumar R, Kutschke G, Lundberg S, Lourenco CM, Mehta R, Naidu S, Nischal KK, Nunes L, Ounap K, Philippart M, Prabhakar P, Risen SR, Schiffmann R, Soh C, Stephenson JB, Stewart $\mathrm{H}$, Stone J, Tolmie JL, van der Knaap MS, Vieira JP, Vilain CN, Wakeling EL, Wermenbol V, Whitney A, Lovell SC, Meyer S, Livingston JH, Baerlocher GM, Black GC, Rice Gl, Crow YJ. Mutations in CTC1, encoding conserved telomere maintenance component 1, cause Coats plus. Nat Genet. 2012;44(3):338-42.

23. Scheinfeld MH, Lui YW, Kolb EA, Engel HM, Gomes WA, Weidenheim KM, Bello JA. The neuroradiological findings in a case of Revesz syndrome. Pediatr Radiol. 2007;37(11):1166-70.

24. Smith EM, Pendlebury DF, Nandakumar J. Structural biology of telomeres and telomerase. Cell Mol Life Sci. 2019;77:61-79.

25. Monoi A, Sugawa M, Kato M, Seki M, Yoshida K, Shiraishi Y, Sakaguchi H, Ogawa S, Takita J. Atypical dyskeratosis congenita diagnosed using whole-exome sequencing. Pediatr Int. 2017;59(8):933-5.

26. Walne AJ, Vulliamy $T$, Beswick $R$, Kirwan M, Dokal I. TINF2 mutations result in very short telomeres: analysis of a large cohort of patients with dyskeratosis congenita and related bone marrow failure syndromes. Blood. 2008;112(9):3594-600.

27. Allingham MJ. Bilateral proliferative retinopathy associated with HoyeraalHreidarsson syndrome, a severe form of dyskeratosis congenita. Ophthalmic Surg Lasers Imaging Retina. 2016;47(4):366-8.

28. Sharma A, Myers K, Ye Z, D'Orazio J. Dyskeratosis congenita caused by a novel TERT point mutation in siblings with pancytopenia and exudative retinopathy. Pediatr Blood Cancer. 2014;61(12):2302-4.

29. D'Amours G, Lopes F, Gauthier J, Saillour V, Nassif C, Wynn R, Alos N, Leblanc T, Capri Y, Nizard S, Lemyre E, Michaud JL, Pelletier VA, Pastore YD, Soucy JF. Refining the phenotype associated with biallelic DNAJC21 mutations. Clin Genet. 2018;94(2):252-8.

30. Shabanova I, Cohen E, Cada M, Vincent A, Cohn RD, Dror Y. ERCC6L2associated inherited bone marrow failure syndrome. Mol Genet Genomic Med. 2018:6(3):463-8.

31. Denny M, Haug SJ, Cunningham ET Jr, Jumper JM. Fanconi anemia presenting as bilateral diffuse retinal occlusive vasculopathy. Retin Cases Brief Rep. 2016;10(2):171-4.

32. Martin-Sanz R, Pena D, Lopez-Miguel A, Coco-Martin MB, Gonzalez-Garcia $\mathrm{H}$, Alvarez-Guisasola FJ, Pastor JC. Coats disease in a patient with Fanconi anemia: a case report. Eur J Ophthalmol. 2015;25(2):182-3.

33. Brummendorf $\mathrm{TH}$, Balabanov $\mathrm{S}$. Telomere length dynamics in normal hematopoiesis and in disease states characterized by increased stem cell turnover. Leukemia. 2006;20(10):1706-16.

34. Asai D, Osone S, Imamura T, Sakaguchi H, Nishio N, Kuroda H, Kojima S, Hosoi H. Allo-SCT in a patient with CRMCC with aplastic anemia using a reduced intensity conditioning regimen. Bone Marrow Transplant. 2012:47(8):1126-7.

35. Duprey PA, Steger JW. An unusual case of dyskeratosis congenita with intracranial calcifications. J Am Acad Dermatol. 1988;19(4):760-2.

36. Kajtar P, Mehes K. Bilateral coats retinopathy associated with aplastic anaemia and mild dyskeratotic signs. Am J Med Genet. 1994;49(4):374-7.

37. McElnea EM, van der Spek N, Smith O, Fitzsimon S, Patel CK, O'Marcaigh A. Revesz syndrome masquerading as bilateral cicatricial retinopathy of prematurity. J AAPOS. 2013;17(6):634-6.

38. Negron D, Colon-Castillo L, Morales-Melecio I, Correa-Rivas M. Association of extensive brain calcifications, myelofibrosis, and retinopathy in a 12-year-old child. Pediatr Dev Pathol. 2008;11(2):148-51. 
39. Riyaz A, Riyaz N, Jayakrishnan MP, Mohamed Shiras PT, Ajith Kumar VT, Ajith BS. Revesz syndrome. Indian J Pediatr. 2007;74(9):862-3.

40. Tamura S, Imamura T, Urata T, Kobayashi M, Gen M, Tomii T, Do J, Osone S, Ishida H, Hosoi H, Kuroda H. Allogeneic hematopoietic cell transplantation for dyskeratosis congenita: a report of 3 cases. J Pediatr Hematol Oncol. 2017;39(7):e394-8.

41. Tomcikova D, Gerinec A, Busanyova B, Gresikova M, Biskup S, Hortnagel K. Why is it necessary to examine retina when the patient suffers from aplastic anemia? Bratisl Lek Listy. 2018;119(5):275-7.

42. Watanabe K, Arakawa Y, Kambe T, Oguma E, Kishimoto H, Koh K. Unrelated allogeneic hematopoietic stem cell transplantation in a patient with Revesz syndrome, a severe variant of dyskeratosis congenita. Pediatr Blood Cancer. 2019;66(1):e27476.

43. Ferreira MSV, Kirschner M, Halfmeyer I, Estrada N, Xicoy B, Isfort S, Vieri M, Zamora L, Abels A, Bouillon AS, Begemann M, Schemionek M, Maurer A, Koschmieder S, Wilop S, Panse J, Brummendorf TH, Beier F. Comparison of flow-FISH and MM-qPCR telomere length assessment techniques for the screening of telomeropathies. Ann N Y Acad Sci. 2020;1466(1):93-103.

44. Ward SC, Savage SA, Giri N, Alter BP, Rosenberg PS, Pichard DC, Cowen EW. Beyond the triad: inheritance, mucocutaneous phenotype, and mortality in a cohort of patients with dyskeratosis congenita. J Am Acad Dermatol. 2018;78(4):804-6.

45. Dokal I. Dyskeratosis congenita. Hematol Am Soc Hematol Educ Program 2011:2011:480-6.

46. Barbaro PM, Ziegler DS, Reddel RR. The wide-ranging clinical implications of the short telomere syndromes. Intern Med J. 2016;46(4):393-403.

47. Walsh MF, Chang VY, KohImann WK, Scott HS, Cunniff C, Bourdeaut F, Molenaar JJ, Porter CC, Sandlund JT, Plon SE, Wang LL, Savage SA. Recommendations for childhood cancer screening and surveillance in DNA repair disorders. Clin Cancer Res. 2017;23(11):e23-31.

48. Du HY, Mason PJ, Bessler M, Wilson DB. TINF2 mutations in children with severe aplastic anemia. Pediatr Blood Cancer. 2009;52(5):687.

49. Ostronoff F, Ostronoff M, Calixto R, Florencio R, Domingues MC, Souto Maior AP, Sucupira A, Tagliari C. Fludarabine, cyclophosphamide, and antithymocyte globulin for a patient with dyskeratosis congenita and severe bone marrow failure. Biol Blood Marrow Transplant. 2007;13(3):366-8.

50. Higgs C, Crow YJ, Adams DM, Chang E, Hayes D Jr, Herbig U, Huang JN, Himes R, Jajoo K, Johnson FB, Reynolds SD, Yonekawa Y, Armanios M, Boulad F, DiNardo CD, Dufour C, Goldman FD, Khan S, Kratz C, Myers KC, Raghu G, Alter BP, Aubert G, Bhala S, Cowen EW, Dror Y, El-Youssef M, Friedman B, Giri N, Helms Guba L, Khincha PP, Lin TF, Longhurst H, McReynolds LJ, Nelson A, Olson T, Pariser A, Perona R, Sasa G, Schratz K, Simonetto DA, Townsley D, Walsh M, Stevens K, Agarwal S, Bertuch AA, Savage SA. Understanding the evolving phenotype of vascular complications in telomere biology disorders. Angiogenesis. 2019;22(1):95-102.

51. Mason JO 3rd, Yunker JJ, Nixon PA, Vail RS, Tsilou E, Giri N, Alter BP. Proliferative retinopathy as a complication of dyskeratosis congenita. Retin Cases Brief Rep. 2009;3(3):259-62.

52. Arish N, Petukhov D, Wallach-Dayan SB. The role of telomerase and telomeres in interstitial lung diseases: from molecules to clinical implications. Int J Mol Sci. 2019;20(12):2996.

53. Giri N, Ravichandran S, Wang Y, Gadalla SM, Alter BP, Fontana J, Savage SA. Prognostic significance of pulmonary function tests in dyskeratosis congenita, a telomere biology disorder. ERJ Open Res 2019;5(4).

54. Teixeira LF, Shields CL, Marr B, Horgan N, Shields JA. Bilateral retinal vasculopathy in a patient with dyskeratosis congenita. Arch Ophthalmol. 2008;126(1):134-5.

55. Tsilou ET, Giri N, Weinstein S, Mueller C, Savage SA, Alter BP. Ocular and orbital manifestations of the inherited bone marrow failure syndromes: Fanconi anemia and dyskeratosis congenita. Ophthalmology. 2010;117(3):615-22.

56. Chai SM, Mathur R, Ong SG. Retinal vasculopathy in Fanconi anemia. Ophthalmic Surg Lasers Imaging. 2009;40(5):498-500.

57. Abdollahi M, Gao MM, Munoz DG. Distinct pattern of neostriatal calcifications in dyskeratosis congenita: a case report and literature review. Clin Neuropathol. 2018;37(6):277-82.

58. Sarper N, Zengin E, Kilic SC. A child with severe form of dyskeratosis congenita and TINF2 mutation of shelterin complex. Pediatr Blood Cancer. 2010;55(6):1185-6.

59. Tsangaris E, Adams SL, Yoon G, Chitayat D, Lansdorp P, Dokal I, Dror Y. Ataxia and pancytopenia caused by a mutation in TINF2. Hum Genet. 2008;124(5):507-13.

60. Bhala S, Best AF, Giri N, Alter BP, Pao M, Gropman A, Baker EH, Savage SA. CNS manifestations in patients with telomere biology disorders. Neurol Genet. 2019;5(6):370.

61. Akaboshi S, Yoshimura M, Hara T, Kageyama H, Nishikwa K, Kawakami T, leshima A, Takeshita K. A case of Hoyeraal-Hreidarsson syndrome: delayed myelination and hypoplasia of corpus callosum are other important signs. Neuropediatrics. 2000;31(3):141-4.

62. Savage SA. Beginning at the ends: telomeres and human disease. F1000Res 2018;7:524

63. Amir M, Khan P, Queen A, Dohare R, Alajmi MF, Hussain A, Islam A, Ahmad F, Hassan I. Structural features of nucleoprotein CST/shelterin complex involved in the telomere maintenance and its association with disease mutations. Cells. 2020;9(2):359.

64. Hu C, Rai R, Huang C, Broton C, Long J, Xu Y, Xue J, Lei M, Chang S, Chen $Y$. Structural and functional analyses of the mammalian TIN2-TPP1-TRF2 telomeric complex. Cell Res. 2017;27(12):1485-502.

65. Nelson ND, Dodson LM, Escudero L, Sukumar AT, Williams CL, Mihalek I, Baldan A, Baird DM, Bertuch AA. The C-Terminal extension unique to the long isoform of the shelterin component TIN2 enhances its interaction with TRF2 in a phosphorylation- and dyskeratosis congenita clusterdependent fashion. Mol Cell Biol. 2018;38(12):e00025-18.

66. Vulliamy T, Beswick R, Kirwan MJ, Hossain U, Walne AJ, Dokal I. Telomere length measurement can distinguish pathogenic from non-pathogenic variants in the shelterin component, TIN2. Clin Genet. 2012;81(1):76-81.

67. Alter BP, Rosenberg PS, Giri N, Baerlocher GM, Lansdorp PM, Savage SA. Telomere length is associated with disease severity and declines with age in dyskeratosis congenita. Haematologica. 2012;97(3):353-9.

68. Keel SB, Scott A, Sanchez-Bonilla M, Ho PA, Gulsuner S, Pritchard CC, Abkowitz JL, King MC, Walsh T, Shimamura A. Genetic features of myelodysplastic syndrome and aplastic anemia in pediatric and young adult patients. Haematologica. 2016;101(11):1343-50.

69. Hoffman TW, van der Vis JJ, van Oosterhout MF, van Es HW, van Kessel DA, Grutters JC, van Moorsel CH. TINF2 gene mutation in a patient with pulmonary fibrosis. Case Rep Pulmonol. 2016;2016:1310862.

70. Pike AM, Strong MA, Ouyang JPT, Greider CW. TIN2 functions with TPP1/POT1 to stimulate telomerase processivity. Mol Cell Biol. 2019;39(21):e00593-18.

71. Townsley DM, Dumitriu B, Liu D, Biancotto A, Weinstein B, Chen C, Hardy N, Mihalek AD, Lingala S, Kim YJ, Yao J, Jones E, Gochuico BR, Heller T, Wu CO, Calado RT, Scheinberg P, Young NS. Danazol treatment for telomere diseases. N Engl J Med. 2016;374(20):1922-31.

\section{Publisher's Note}

Springer Nature remains neutral with regard to jurisdictional claims in published maps and institutional affiliations. 